Jurnal

\title{
Coronary Intervention for Stable Angina Pectoris: The use of Fractional Flow Reserve as a decision making tool for Coronary Angioplasty
}

\author{
Januar Wibawa Martha
}

Department of Cardiology and Vascular Medicine Padjadjaran University/Hasan Sadikin Hospital
Coronary angioplasty is a definitive, percutaneous intervention to improve myocardial oxygen supply. The benefit of coronary angioplasty for stable angina pectoris is still a controversy. The COURAGE trial had shown that angioplasty for stable angina pectoris gave no additional benefit compared with optimal medical therapy, while the recently done FAME II trial showed the opposite. FAME II trial proved that angioplasty could reduce MACEs in stable angina pectoris patients. The conflicting results from COURAGE and FAME II trials is due to the difference in decision making methodology used for angioplasty. COURAGE used plain angiogram while FAME II utilized Fractional Flow Reserve (FFR) as a tool to decide whether a lesion should undergo angioplasty. The result of FAME II demonstrate FFR is far more reliable to determine coronary lesion which cause ischemia, hence a better decision making tool for angioplasty. The specificity of FFR is proven high, while angiography has an excessive false positives. The use of FFR before angioplasty is still low although there is a considerable evidence that FFR is a better decion making tool for angioplasty compared to angiography. Health economic analysis displayed the use of FFR for stable angina pectoris is cost effective in the long term.

(J Kardiol Indones. 20 I2;33:43-7)

Keywords: Coronary angioplasty - Stable angina pectoris - Fractional Flow Reserve 
Jurnal

Kardiologi Indonesia

J Kardiol Indones. 2013;34:43-7

ISSN $0126 / 3773$

\title{
Intervensi Koroner pada pasien Angina Pekłoris Stabil: Penggunaan Fractional Flow Reserve sebagai Alat Pengambil Keputusan Angioplasti
}

\author{
Januar Wibawa Martha
}

\begin{abstract}
Tindakan angioplasti koroner adalah tindakan intervensi perkutan yang bertujuan untuk memperbaiki suplai oksigen miokardium. Manfaat tindakan angioplasti pada kasus angina pektoris stabil hingga saat ini masih diperdebatkan. Penelitian COURAGE menunjukkan tindakan angioplasti pada angina pektoris stabil tidak memberi manfaat tambahan dibandingkan terapi medikal optimal. Namun sebaliknya penelitian FAME II membuktikan tindakan angioplasti dapat mengurangi kejadian kardiovaskuler pasien-pasien angina pektoris stabil. Kesimpulan yang berbeda dari kedua studi ini disebabkan perbedaan alat pengambil keputusan angioplasti. Pada COURAGE, keputusan angioplasti didasarkan pada penilaian angiogram sedangkan pada FAME II menggunakan pengukuran Fractional Flow Reserve (FFR). Ini menunjukkan penggunaan FFR terbukti lebih terpercaya untuk menentukan derajat stenosis arteri koroner yang menyebabkan iskemia. Spesifisitas FFR untuk menentukan iskemia juga sangat tinggi, sedangkan angiografi memiliki angka positif palsu yang cukup tinggi. Hingga saat ini penggunaan FFR pra-angioplasti masih rendah, meskipun telah banyak bukti yang menunjukkan FFR merupakan alat pengambil keputusan angioplasti yang lebih baik dibandingkan angiografi. Studi ekonomi kesehatan juga membuktikan pemakaian FFR dapat menghemat biaya kesehatan dalam jangka panjang.
\end{abstract}

(J Kardiol Indones. 2013;34:43-7)

Kata kunci: Angioplasti koroner - Angina Pektoris Stabil - Fractional Flow Reserve

$\mathrm{H}$ asil penelitian pendahuluan FAME II yang baru-baru ini dipresentasikan pada EuroPCR 2012 memberikan kegairahan baru intervensi kardiologi pada angina pektoris stabil. Pasca studi COURAGE tahun 2007, angioplasti pada angina pektoris stabil mengalami masa surut. Ini disebabkan kesimpulan studi COURAGE yang menunjukkan bahwa angioplasti pada pasien

\section{Alamat Korespondensi:}

Januar Wibawa Martha, MD, Departemen Kardiologi dan Kedokteran Vaskuler, Universitas Padjadjaran, Bandung. Email: jwmartha@ gmail.com angina pektoris stabil tidak memberikan manfaat tambahan dibandingkan terapi medikal optimal. ${ }^{1}$

Studi FAME II membuktikan sebaliknya yaitu penggunaan fraksi aliran fungsional (FFR=Fractional Flow Reserve) sebelum tindakan angioplasti pada pasien angina pektoris stabil memberikan hasil yang lebih baik dibandingkan dengan hanya terapi medikal optimal (OMT=Optimal Medical Therapy). Studi FAME II bahkan dihentikan sebelum waktunya karena kelompok yang hanya mendapat terapi medikal optimal banyak yang mengalami perawatan rumah sakit ulang dan revaskularisasi, sehingga Data Safety Board mengang- 
gap tidak etis untuk melanjutkan merekrut kelompok yang hanya menerima terapi medikal optimal. ${ }^{2}$

Mengapa hasil studi FAME II bertentangan dengan COURAGE? Ini disebabkan penentuan tindakan angioplasti pada studi FAME II berbeda dengan studi COURAGE. Pada COURAGE, penentuan tindakan angioplasti (stenosis koroner) hanya didasarkan pada gambaran angiogram, sedangkan FAME II mengandalkan hasil FFR untuk menentukan apakah stenosis koroner perlu dilakukan angioplasti atau tidak. ${ }^{1,2}$ Studi FAME II membuktikan keunggulan FFR sebagai alat diagnostik stenosis yang lebih baik dibandingkan angiografi konvensional.

Dalam beberapa tahun terakhir ini berkembang paradigma baru dalam dunia kardiologi intervensi, yaitu angioplasti fungsional. Angioplasti fungsional adalah penentuan tindakan angioplasti (ada tidak nyastenosis signifikan) bukan atas dasar angiografi koroner dua dimensi, namun berdasarkan fungsional yaitu stenosis yang ditentukan berdasarkan FFR. 3,4

Fractional Flow Reserve pada dasarnya mengukur dan membandingkan aliran darah pre-stenotik dan aliran darah post-stenotik. Pada arteri koroner yang menderita stenosis berat, terjadi penurunan aliran darah post stenotik yang signifikan. Berdasarkan persamaan matematika, aliran (flow) pre dan post stenotik dapat dirubah menjadi tekanan (pressure) pre dan post stenotik. Pengukuran tekanan pre-stenotik biasanya memakai tekanan aorta, sedangkan tekanan post-stenotik diukur secara langsung menggunakan pressure wire yang ditempatkan distal dari lesi stenosis. Prosedur pengukuran FFR selanjutnya adalah memberikan aliran hiperemis maksimal yang biasanya diperoleh melalui infus adenosine intravena. Angka FFR didapat dengan membagi tekanan poststenotik dan tekanan aorta (Gambar 1). ${ }^{5}$ Berdasarkan konsensus, angka FFR kurang dari 0.80 dipakai sebagai cut-off stenosis yang bermakna.

Penelitian yang menelaah penggunaan FFR dalam pengambilan keputusan angioplasti adalah studi FAME dan FAME II diatas. Studi FAME membuktikan bahwa penggunaan FFR, bukan angiografi, dalam penentuan tindakan angioplasti menghasilkan penurunan penggunaan stent hingga $1 / 3$ nya. ${ }^{2}$ Pada follow up selama 1 tahun, penggunaan FFR dapat mengurangi angka MACE sebesar 28\%. Kesimpulan yang penting dari studi ini adalah FFR menjadi alat penentuan keputusan (decision making tool) tindakan angioplasti yang lebih terpercaya dibandingkan angiografi konvensional. ${ }^{2,6,7}$

Selama ini telah diakui adanya keterbatasan

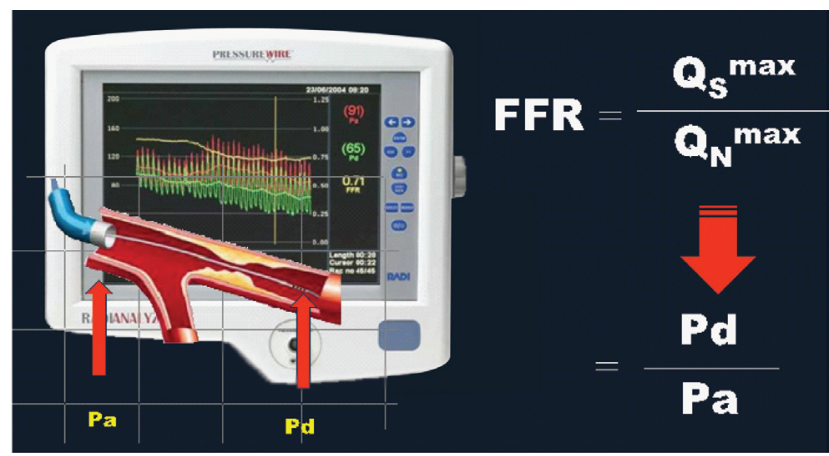

Gambar 1. Pengukuran FFR yang membandingkan tekanan distal lesi stenosis dan tekanan aorta

angiografi konvensional dalam menentukan derajat stenosis arteri koroner. Angiografi konvensional menilai stenosis berdasarkan gambaran fluoroskopi arteri koroner yang diberi kontras. Pada kebanyakan kasus, penentuan stenosis hanya didasarkan pada perkiraan gambaran dua dimensi ini. Sebagai fitur lanjutan angiografi konvensional adalah angiografi kuantitatif yang merupakan perbaikan dari angiografi konvensional. Angiografi kuantitatif (Quantitative Coronary angiography - QCA) didasari pada gambaran lumen koroner yang diberi software khusus untuk menilai tepi arteri, sehingga dapat menilai derajat stenosis koroner secara komputerisasi. ${ }^{8}$

Pada kasus-kasus yang secara angiografi normal atau terdapat stenosis koroner yang sangat ringan, aliran koroner yang baik (aliran TIMI 3) dengan keluhan atipikal dan faktor risiko minimal maka pengukuran FFR mungkin tidak diperlukan. Sebaliknya pada kasus stenosis koroner yang sangat berat, aliran koroner yang buruk (aliran TIMI 1 atau 2), keluhan angina yang khas dengan banyak faktor risiko seringkali pemeriksaan FFR juga tidak diperlukan. Namun pada kasus-kasus dengan stenosis koroner yang marginal (intermediate lesion), pemeriksaan FFR sangat dibutuhkan untuk menghindari kesalahan dalam pengambilan keputusan angioplasti. ${ }^{6,7}$

Namun demikian, ternyata tidak sedikit kasus stenosis koroner yang jelas-jelas berat secara angiografi, namun ternyata FFR tidak menunjukkan adanya stenosis signifikan. Contoh kasus seperti dibawah ini (Gambar 2)

Pada kasus diatas, angiografi konvensional secara kuantitatif menunjukkan derajat stenosis $85 \%$ yang hampir pasti akan dilakukan angioplasti, namun FFR membuktikan aliran masih dalam batas normal (FFR $>0,80)$. Selain itu, pemeriksaan iskemia objektif pra 


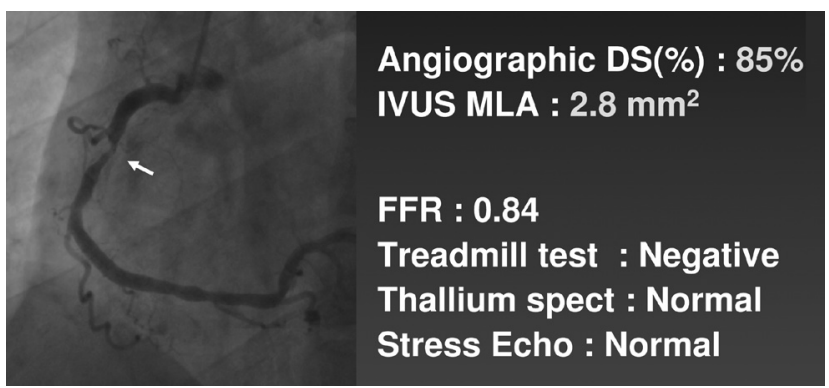

Gambar 2. Ketidaksesuaian antara angiografi, pemeriksaan iskemik noninvasif dan FFR

DS: Degree of Stenosis, IVUS MLA: Intravascular Ultrasound Minimum Luminal Area

tindakan seperti Treadmill test, Stress Echo dan Thallium test juga negatif. Oleh karena itu pasien tersebut sebaiknya tidak dilakukan angioplasti. Pelajaran yang dapat diambil dari kasus diatas adalah hasil angiografi seringkali tidak sesuai dengan hasil pemeriksaan iskemia objektif secara noninvasif, sedangkan FFR memiliki korelasi yang sangat baik dengan hasil pemeriksaan noninvasif. ${ }^{9}$ Penelitian lain juga menghasilkan kesimpulan yang sama. Pada seri kasus yang dilakukan di Asan Medical Center di Seoul, FFR > 0,80 memiliki tingkat spesifitas 100\%. Artinya FFR normal (sering disebut FFR negatif) sudah pasti membuktikan tidak ada stenosis yang bermakna. ${ }^{4}$

Frekuensi penggunaan FFR sebagai alat pengambilan keputusan angioplasti memang masih rendah. Selain modulnya yang cukup mahal, bahan habis pakai seperti pressure wire juga tidak murah. Kendala lainnya yang sering dikeluhkan adalah manipulasi pressure wire

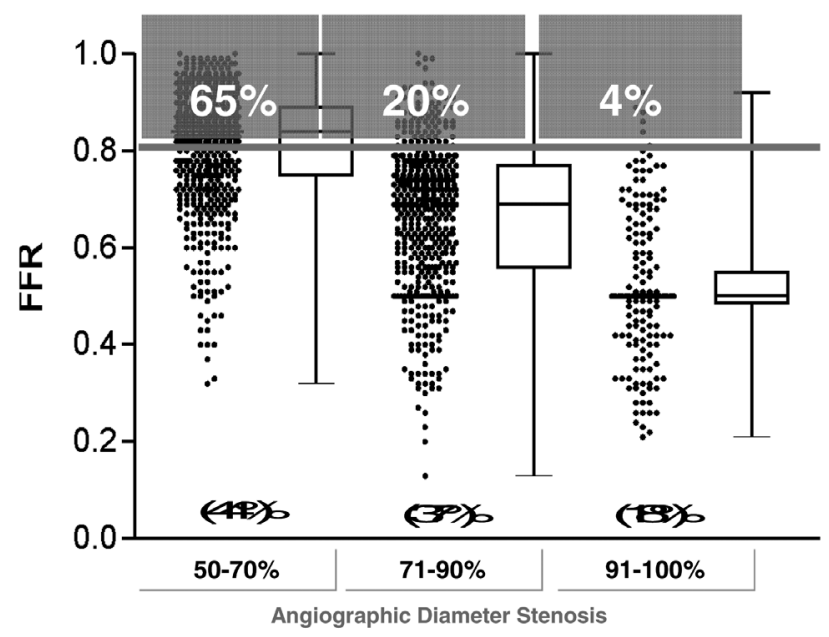

Gambar 3. Positif palsu stenosis koroner pada pemeriksaan angiografi dibandingkan FFR ${ }^{2}$ yang tidak mudah dan penggunaan adenosine yang ditakutkan menyebabkan bradikardia. Disamping itu pengukuran FFR dikhawatirkan akan menambah lama procedure time, yang dapat berpengaruh pada alur pasien-pasien secara keseluruhan.

Data yang ada sebelum studi FAME adalah FFR diukur pada kurang dari 20\% dari seluruh tindakan angioplasti.Bahkan Dr deBruyne yang merupakan peneliti FAME II memperkirakan angka penggunaan FFR bervariasi dan hanya 5-8\% dari seluruh tindakan angioplasti. ${ }^{2}$ Namun demikian, terdapat kecenderungan peningkatan penggunaan FFR di berbagai pusat angioplasti di dunia. Berkaitan dengan ini, penulis berkesempatan mengunjungi Asan Medical Center di Seoul dimana disana paradigma pengukuran stenosis fungsional dengan FFR sudah diaplikasikan dalam tindakan sehari-hari. Pada laboratorium kateterisasi Asan Medical Center, penggunaan FFR pra angioplasti dilakukan pada $100 \%$ lesi dengan stenosis kurang dari $80 \%$.

Berapa banyak terjadi ketidaksesuaian (mismatch) antara angiografi dan FFR? Ternyata dari beberapa penelitian, angkanya sangat besar. Gambar 3 menunjukkan kejadian positif palsu lesi stenosis yang diukur berdasarkan angiografi koroner bila dibandingkan dengan pengukuran FFR. Studi FAME mengambarkan bahwa pada stenosis $50-70 \%$ secara angiografi, 65\% nya memiliki FFR normal. ${ }^{2}$ Artinya bila kita meyakini FFR sebagai standar baku penentuan stenosis yang signifikan, dan semua stenosis $50-70 \%$ secara angiografi dilakukan angioplasti, $65 \%$ nya adalah suatu tindakan yang tidak perlu. Untuk stenosis yang lebih berat, angka positif palsu angiografi lebih kecil. Pada lesi stenosis $71-90 \%$ secara angiografi, $20 \%$ memiliki FFR normal dan pada lesi stenosis $>90 \%$, hanya $4 \%$ yang menunjukkan FFR normal. ${ }^{2}$

Bagaimana dengan guideline? Pada panduan European Society of Cardiology, penggunaan FFR termasuk dalam kelas $1 .{ }^{10}$ Sampai tulisan ini dibuat, panduan American College of Cardiology menempatkan penggunaan FFR dalam kelas 2A. ${ }^{11}$ Kedua panduan ini sangat menganjurkan penggunaan FFR sebagai alat diagnostik sebelum tindakan angioplasti.

Pertanyaan yang sering dikemukakan adalah: akankah pemakaian FFR tersebut malah menambah biaya operasional angioplasti? Pressure wire yang digunakan memang menambah biaya dan tidak dapat dipakai ulang. Namun pada penelitian di berbagai negara di Eropa, pemeriksaan FFR justru malah mengurangi biaya tindakan angioplasti. Di Perancis, pemakaian 
FFR dapat mengurangi biaya tindakan setara dengan 1270 dollar per pasien.Studi cost effectiveness yang dilakukan di Amerika Serikat menunjukkan pemakaian FFR mengurangi biaya 675 dollar per tindakan. ${ }^{12}$

Dari segi pasien, penggunaan FFR pra angioplasti sangat menguntungkan karena dapat mengurangi pemasangan stent yang tidak perlu, yang tentu saja akan mengurangi biaya. Luaran (outcome) klinis yang didapatkan dengan penggunaan FFR juga lebih baik yang tergambarkan dengan lebih rendahnya MACE. ${ }^{2}$ Untuk masalah keamanan, FFR lebih aman karena tindakan angioplasti bukannya tanpa risiko disamping zat kontras yang dipakai juga akan lebih sedikit. Kesimpulannya, penggunaan FFR menjadikan angioplasti lebih murah, hasil yang lebih baik, dan lebih aman untuk pasien.

\section{Daftar Pustaka}

1. Boden WE, O’Rourke MA, Teo KK, Hartigan PM, Maron DJ, Kostuk WJ, et al for the COURAGE Trial Research Group. Optimal medical therapy with or without PCI for Stable Coronary Disease. N Engl J Med 2007; 356:1503-1516

2. Tonino PAL, De Bruyne B, Pijls NH, Siebert, U, Ikeno F, Veer $\mathrm{M}$, et al. Fractional flow reserve versus angiography for guiding percutaneous coronary angiography. N Engl J Med 2009; 360: 360: 213-224

3. Hakeem A, Mouhamad A, Leesar MA. Fractional flow reserve: a new paradigm for diagnosis and management of coronary artery disease. Interv Cardiology 2012; 4:1, 61-71

4. Park SJ, Ahn JM, Kang SJ. Paradigm Shift to Functional
Angioplasty: New Insights for Fractional Flow Reserve- and Intravascular Ultrasound-Guided Percutaneous Coronary Intervention . Circulation2011;124:951-957

5. Sharif F, Trana C, Muller O, De Bruyne B. Practical tips and tricks for the measurement of fractional flow reserve. Cath Cardiovasc Interv 2010;76(7):978-85.

6. Layland J, Macisaac AM, Burns AT, Whitbourn RJ, Wilson AM.Integrated coronary physiology in percutaneous intervention: a new paradigm in interventional cardiology. Heart Lung Circ. 2011; 20:641-6

7. Melikian N, De Bondt P, Tonino P, De Winter O, Wyffels E, Bartunek J, et al. Fractional flow reserve and myocardial perfusion imaging in patients with angiographic multivessel coronary artery disease. JACC Cardiovasc Interv. 2010;3(3):307-14

8. Yong AS, Ng AC, Brieger D, Lowe HC, Ng MK, Kritharides L. Three-dimensional and two-dimensional quantitative coronary angiography, and their prediction of reduced fractional flow reserve. Eur Heart J. 2011;32(3):345-53.

9. Beleslin B, Dobric M, Sobic-Saranovic D, Giga V, Stepanovic J, Djordjevic-Dikic A, et al. Fractional flow reserve and myocardial viability as assessed by SPECT perfusion scintigraphy in patients with prior myocardial infarction. J Nucl Cardiology 2010;17(5):817-24.

10. Wijns W, Kolh P, Danchin N, Di Mario C, Falk V, Folliguet T, et al. Guidelines on myocardial revascularization. Eur Heart J 2010;31, 2501-2555

11. Levine GN, Bates ER, Blankenship JC, Bailey SR, Bittl JA, Cercek B, et al. ACCF/AHA/SCAI Guideline for Percutaneous Coronary Intervention. Circulation2011;124:e574-e651

12. Morrone D, Weintraub WS. Interventional cardiology: Costeffectiveness of PCI guided by fractional flow reserve. Rev Cardiology 2011; 8:3, 125-126 